\title{
Hanford Phosphate Precipitation Filtration Process Evaluation
}

by

B. W. Walker

Westinghouse Savannah River Company

Savannah River Site

Aiken, South Carolina 29808

D. McCabe

A document prepared for TO BE SHARED WITH OTHER DOE SITES at , , from - .

DOE Contract No. DE-AC09-96SR18500

This paper was prepared in connection with work done under the above contract number with the U.S.

Department of Energy. By acceptance of this paper, the publisher and/or recipient acknowledges the U.S. Government's right to retain a nonexclusive, royalty-free license in and to any copyright covering this paper, along with the right to reproduce and to authorize others to reproduce all or part of the copyrighted paper.

DITHEUTON OF THIS DOCUMENT IS UNLIMITED

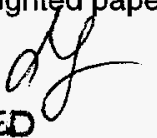




\section{DISCLAIMER}

This report was prepared as an account of work sponsored by an agency of the United States Government. Neither the United States Government nor any agency thereof, nor any of their employees, makes any warranty, express or implied, or assumes any legal liability or responsibility for the accuracy, completeness, or usefulness of any information, apparatus, product, or process disclosed, or represents that its use would not infringe privately owned rights. Reference herein to any specific commercial product, process, or service by trade name, trademark, manufacturer, or otherwise does not necessarily constitute or imply its endorsement, recommendation, or favoring by the United States Government or any agency thereof. The views and opinions of authors expressed herein do not necessarily state or reflect those of the United States Government or any agency thereof.

This report has been reproduced directly from the best available copy.

Available to DOE and DOE contractors from the Office of Scientific and Technical Information, P. O. Box 62, Oak Ridge, TN 37831; prices available from (423) 576-8401.

Available to the public from the National Technical Information Service, U. S. Department of Commerce, 5285 Port Royal Road, Springfield, VA 22161. 


\section{DISCLAIMER}

Portions of this document may be illegible electronic image products. Images are produced from the best available original, document. 
WSRC-TR-97-00352

Rev. 0

\section{Distribution}

W.B. Van Pelt, 676-T

W.L. Tamosaitis, 773-A

R.A. Peterson, 773-A

B.A. Reynolds, PNNL

J.G.H. Geeting, PNNL

C.P. McGinnis, ORNL

C.A. Nash, 773-42A 
WSRC-TR-97-00352

Revision 0

Keywords: Cross-flow

Filtration

Retention: Permanent

Hanford Phosphate Precipitation Filtration Process Evaluation (U)

September 30, 1997

B.W. Walker, 773-42A

D.J. McCabe, $773-43 \mathrm{~A}$

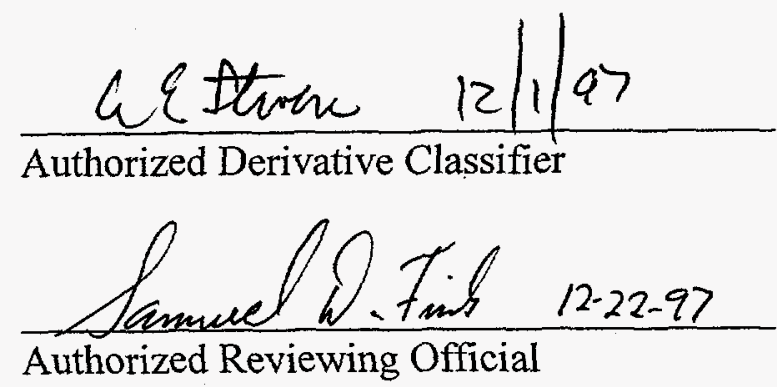

Savannah River Technology Center

Westinghouse Savannah River Company

Aiken, SC 29808

Prepared for the Department of Energy

Office of Science and Technology

Tanks Focus Area Program

Technical Task Plan SR1-6-WT-41 
WSRC-TR-97-00352

Page 2 of 14

\section{Summary}

Cross-flow filtration is being evaluated as a pretreatment in the proposed treatment processes for aqueous High Level radioactive wastes at Hanford to separate solid precipitate from aqueous waste.

A suitable Hanford simulant was created per Oak Ridge National Laboratory personnel recommendations that are jointly working on this project. Filter studies were then conducted to evaluate whether 0.5 micron cross-flow sintered metal Mott filters can perform solid-liquid separation of a phosphate precipitate in a High Level radioactive wash solution from one of Hanford's processes. Analysis of filtration data lead to the following conclusions:

- Cross-flow filtration of simulant gave a filtrate flux maximum of $0.1 \mathrm{gpm} / \mathrm{f}^{2}$ with 0.5 micron Mott filters. Use of the 0.5 micron Mott filter does not give good solid-liquid separation because there is a problem with the precipitate formation in the filtrate after the filtration process. Post-precipitation of phosphate solids, indicate that the solution was not at equilibrium and further work is needed to understand solution kinetics.

- Filtrate production is controlled by the transmembrane pressure drop across the filter.

- Filtrate production is not controlled by axial velocity of the slurry through the filters.

- Filtrate production decreases significantly with time indicating filter fouling.

- The Mott filter was effectively cleaned using 2 wt $\% \mathrm{NaOH}, 2$ wt $\%$ oxalic acid, and deionized water treatments.

\section{Introduction}

The purpose of this filter study was to evaluate cross-flow filtration as effective solidliquid separation technology for treating Hanford wastes, outline operating conditions for equipment, examine the expected filter flow rates, and determine proper cleaning.

A proposed Hanford waste pre-treatment process uses sodium hydroxide at high temperature to remove aluminum from sludge. This process also dissolves phosphates. ${ }^{2}$ Upon cooling to 40 degrees centigrade the phosphates form a $\mathrm{Na}_{7}\left(\mathrm{PO}_{4}\right)_{2} \mathrm{~F} \cdot 9 \mathrm{H}_{2} \mathrm{O}$ precipitate which must be removed prior to further treatment.

Filter studies were conducted with a phosphate slurry simulant to evaluate whether 0.5 micron cross-flow sintered metal Mott filters can separate the phosphate precipitate from the wash solutions. The simulant was recirculated through the filters at room temperature and filtration performance data was collected. 
WSRC-TR-97-00352

Page 3 of 14

\section{$\underline{\text { Solid/Liquid Separation Method Selection }}$}

Although numerous solid/liquid separation technologies are commercially available, few are adaptable to high radiation fields.' However, the In-Tank Precipitation process at the Savannah River Site uses cross-flow filters made of seamless sintered stainless steel. The filter elements are welded to the housing and contain no polymeric components. This design limits maintenance requirements to chemical cleaning and pump maintenance, which can be done remotely. Cross-flow filters can concentrate slurries to relatively high weight loadings while maintaining filtrate production rates.

\section{Testing Strategy}

Laboratory filtration equipment is useful for scoping activities identifying significant impacts to filter performance. Filtrate fluxes are generally higher with laboratory scale equipment than those observed at production scale. Higher fluxes on small-scale equipment have been attributed to more effective backpulsing and chemical cleaning.

The accuracy and confidence of results obtained by use of simulated versus actual waste depend on several factors. Because these factors are not fully understood for filtration of sludge, comparisons are needed between simulants and actual waste.

In the case of phosphate precipitates, the physical characteristics are likely comparable to the actual waste. This is because the material has been identified, and is a new precipitate which has not undergone aging in waste tanks. However the rate of cooling which forms the precipitate is critical to its morphology. ${ }^{2}$

\section{Experimental}

\section{Simulant Preparation}

Simulants were developed for testing of the cross-flow filtration processes by personnel with a waste tank chemistry background at Oak Ridge National Laboratory (ORNL) ${ }^{2}$.

Deionized water (10 liters) containing 38.9 grams/liter of Na2HPO4 and 11.8 grams/liter $\mathrm{NaF}$ was heated to 80 degrees $\mathrm{C}$. Ten liters of 6 molar $\mathrm{NaOH}$ was also prepared at this temperature and the two solutions were then mixed. The final solution was cooled overnight in the Parallel Rheology Experimental Filter (PREF) feed tank. The phosphate precipitate had formed by the next morning.

As the temperature is decreased, solids begin forming at about 40 degrees centigrade. The form of the solid depends on the cool down rate and the temperature. ${ }^{2}$ If the solution is rapidly cooled, small sticky crystals reportedly form. If the solution is held at 
WSRC-TR-97-00352

Page 4 of 14

temperatures near 35 to 40 degrees centigrade a surface coating reportedly builds up on contact surfaces over a period of days or weeks. In this test the solution was rapidly cooled and allowed to sit overnight at room temperature (approximately 25 degrees Centigrade). The small, sticky crystals formed appeared opaque and spherical after the overnight cooling. The temperature of the slurry was maintained at 25-27 degrees centigrade throughout the experiment using a constant temperature heater cooler which recirculated water through a coil placed in the feed tank.

\section{Cross-flow Filter Operating Conditions}

Cross-flow filtration experiments were performed with the simulant using the Parallel Rheology Experimental Filter (PREF) shown schematically in Sketch 1. Each test involved measuring the filtrate flux under a variety of conditions. The two independent variables for these tests were the transmembrane pressure drop and axial velocity. Transmembrane pressure drop is defined as the sum of slurry pressure entering and exiting the filter divided by 2 minus the pressure of the filtrate as it leaves the filter. Axial velocity is defined as the speed that the slurry is moving inside the filter. The conditions for the test are listed in Table 1. The test settings of variables were determined using a statistical model to cover low, high, and intermediate points of the variable ranges. The order of the variable settings was also varied to minimize experimental errors associated with taking data points in the same area at the same time during the experiment. A backpulse was performed following each change in the test conditions. Measurements were taken at each test condition for a period of 1 hour. Data points were taken every 10 minutes by technicians. In addition, a data acquisition system recorded process parameters every minute in the event that more detail was needed. Following the completion of each test, a statistical analysis determined the dependence of filtrate flux for those test conditions as a function of transmembrane pressure drop and axial velocity. An additional analysis was performed to determine the dependence of filter performance on time (used as an indication of filter fouling).

\section{Table 1 - Test settings}

\begin{tabular}{lll} 
Setting Number & Pressure (psig) & Velocity (ft/s) \\
\cline { 2 - 3 } $1-7$ & 15 & 1.75 \\
$8-14$ & 20 & 2.5 \\
$15-21$ & 20 & 1.0 \\
$22-28$ & 15 & 1.75 \\
$29-35$ & 10 & 1.0 \\
$36-42$ & 10 & 2.5 \\
$43-49$ & 15 & 1.75
\end{tabular}




\section{Equipment Description}

The cross-flow filters were fabricated by Mott Metallurgical Corporation of Farmington, Conn. and are seamless tubes. Mott filters were 0.0625 inches thick and 0.5 inch inner diameter. A progressive cavity positive displacement pump manufactured by Moyno Industrial Products of Springfield, Ohio provided slurry flow during the filtration study.

The Parallel Rheological Experimental filter apparatus and associated equipment used in the filtration study are shown in Sketch 1.

Sketch 1.

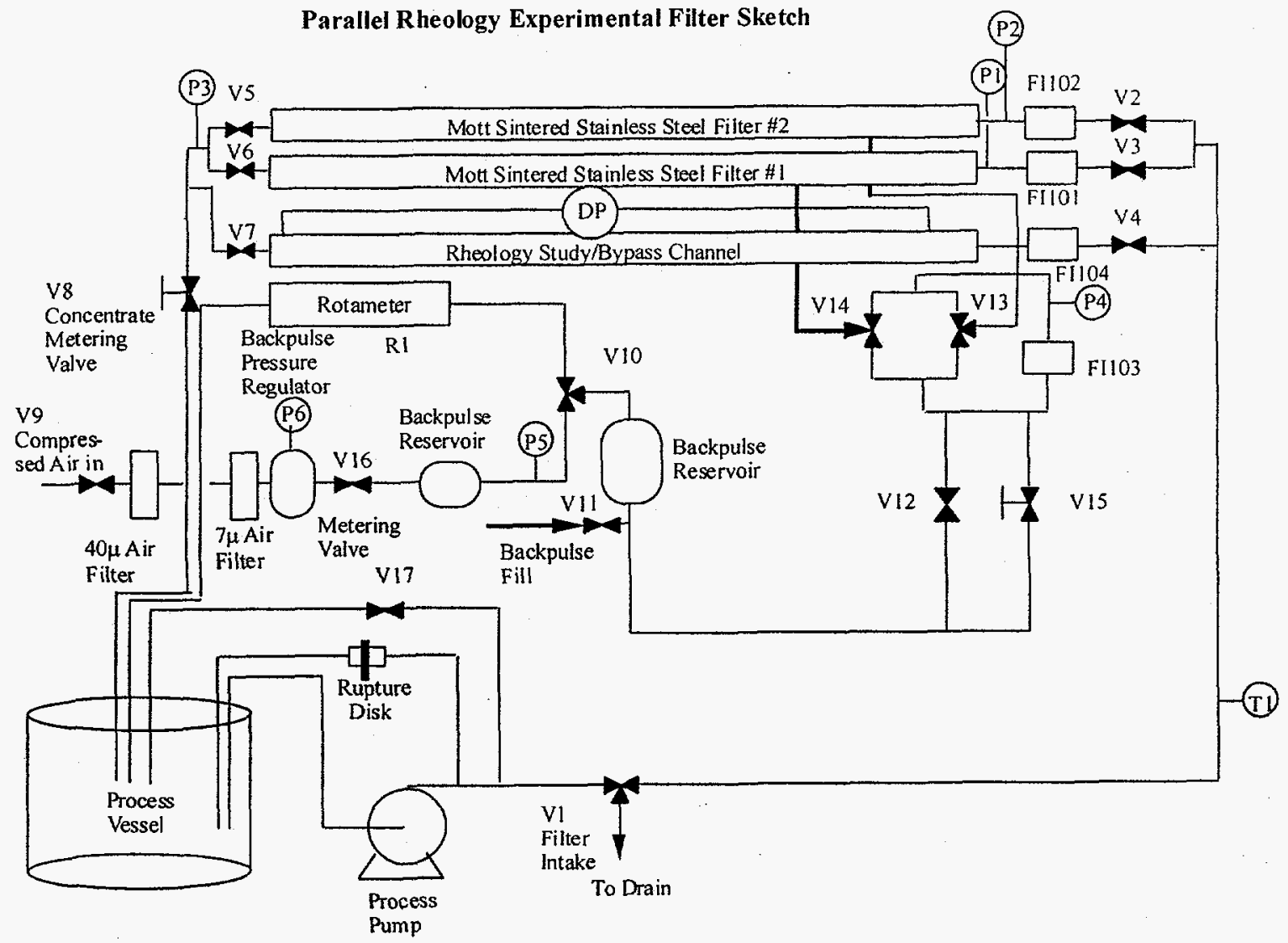




\section{Filtration Mechanism}

In cross-flow filtration the fluid to be filtered flows in parallel to the membrane surface and generates shearing forces and/or turbulence across the filter medium which influences the formation of a filter cake or particle deposition in filter pores.

Cross-flow filtration can be separated into two areas of operation. ${ }^{3}$ In the first area of operation, the axial velocity is sufficient to remove any solids from the surface of the filter. Thus, there is not an accumulation of filter cake on the surface of the filter and any decrease in filter performance is attributed to the deposition of solids within the filter pores. This area of operation is usually associated with dilute feed streams, high axial velocities and low pressure drops. Under these conditions, increasing the axial velocity of the feed stream concentration will have little impact on filtrate production rates. However, increases in transmembrane pressure drop will produce significant increases in filtrate flow rates. During this test the filtrate production increased significantly with increasing transmembrane pressure drop indicating that deposition of solids is occurring in the filter pores.

In the second area of operation, normally when more concentrated feed streams are employed, a higher axial velocity is needed to keep the surface of the filter free of deposited solids. If the axial velocity is not sufficient, a cake of solids will deposit on the surface of the filter. Under these conditions, an increase in the axial velocity will increase the rate of transport of solids from the surface of the filter, and thus decrease the thickness of the filter cake, producing an increase in filter performance. The surface filter cake will cause a decrease in filter performance when an excessive thickness of filter cake is deposited. However an increase in pressure without increasing the axial velocity will only produce a thicker or more compressed cake and will not yield any further increase in filter performance. For this test the filtrate production does not increase significantly with increasing axial velocity indicating that a filter cake is not forming on the filter surface.

\section{Filtration Results}

During the filtration test it was very difficult to maintain the target pressures and velocities of the slurry at steady state. From filtrate flux data it has been determined that cross-flow filtration of this simulant gives a filtrate flux range of 0.02 to $0.1 \mathrm{gpm} / \mathrm{f}^{2}$. 
Figure 1 contains a plot of filtrate flux as a function of axial velocity for the slurry and two Mott 0.5 micron filters in parallel. If a filter cake does not form on the surface of the filter, increases in axial velocity will not decrease the depth of a filter cake and thus improve filtration performance. Linear regression analysis of the data reveals that filtrate flux does not increase significantly in response to increases in axial velocity suggesting that a filter cake is not forming on the filter surface. This also shows that back transport of material from the surface of the filter is not dictating filtrate flux and that a filter cake is not forming on the filter surface. Although the data appears to have a large variance it should be noted that the transmembrane pressure is also being varied during these statistically-designed experiments. Note that these predictions are valid only over the range of operating conditions outlined in Table 1 of the Experimental Section of this report.

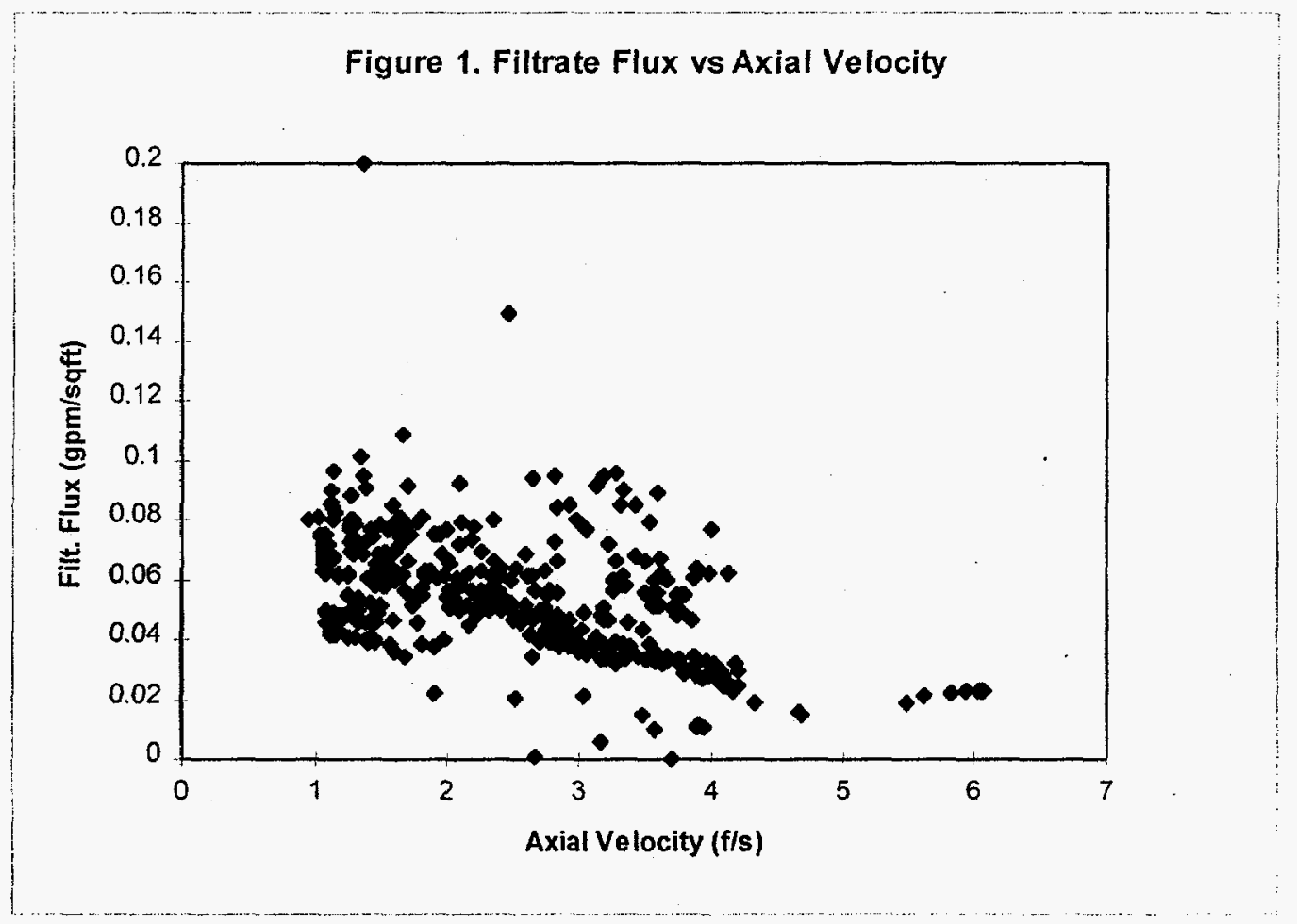


Figure 2 contains a plot of filtrate flux as a function of transmembrane pressure drop for the slurry showing that an increase in transmembrane pressure drop gives a significant increase in filter performance. The statistical analysis model developed from linear regression predicts the following dependence of filtrate flux on filter transmembrane differential pressure.

$\mathrm{Q}=0.0022 \mathrm{P}+0.01895$

where $\mathrm{Q}=$ filtrate flux $\left(\mathrm{gpm} / \mathrm{f}^{\mathrm{f}}\right)$ and $\mathrm{P}=$ transmembrane differential pressure The $95 \%$ confidence interval for the filter transmembrane differential pressure coefficient is $0.0031<\mathrm{cl}<0.0013$.

The dependency of the filtrate flux on transmembrane pressure drop indicates that there is a deposition of particles in the pores of the filter and extending to barely cover the surface of the filter.

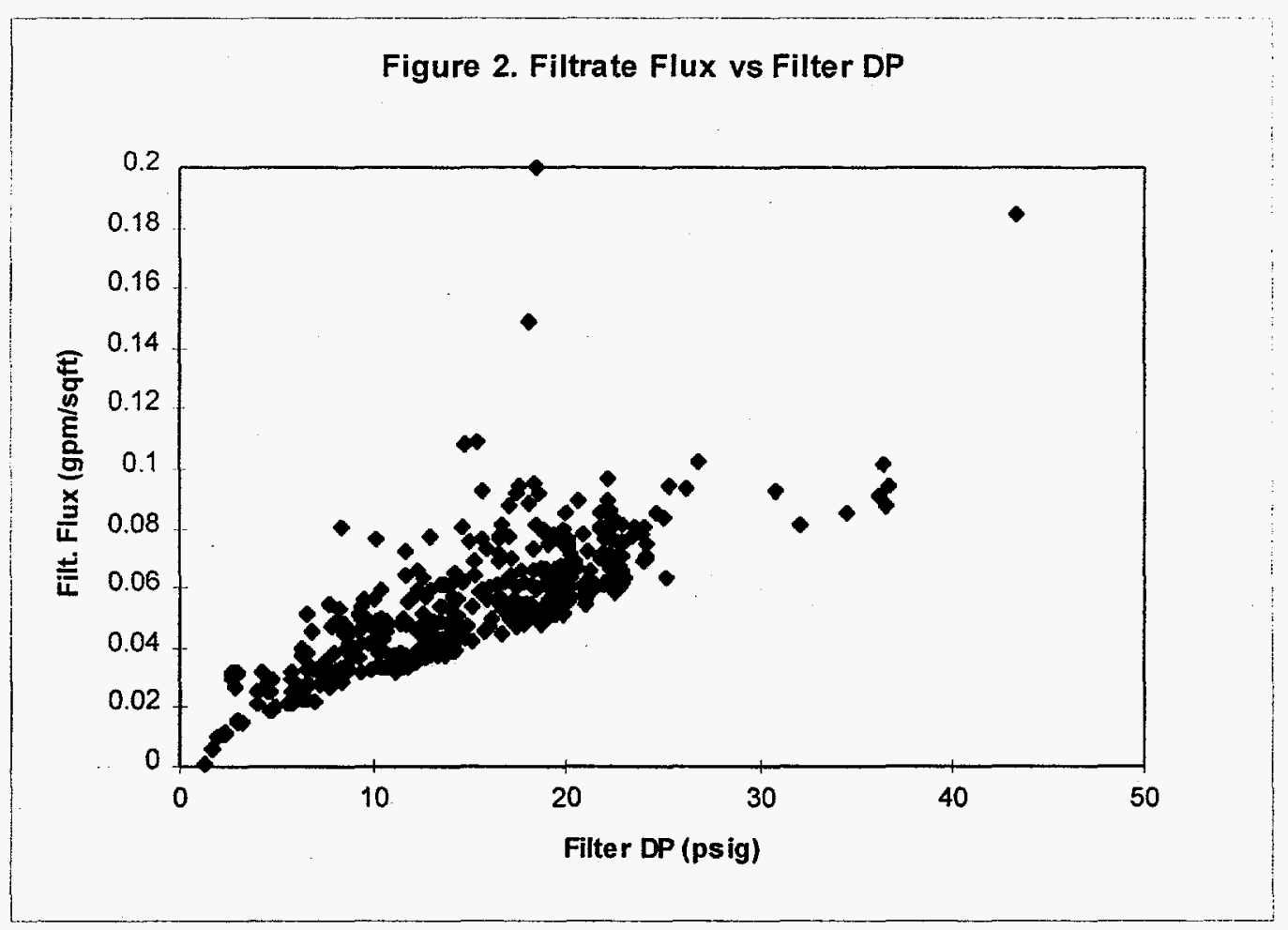


Figure 3 is a plot of the filtrate flux versus the time showing that filtrate production decreases significantly with time. The statistical linear model developed yielded an equation to describe the filtrate flow rate as

$Q=-9.5 e^{-5} T+.074$

where $\mathrm{Q}=$ filtrate flux $\left(\mathrm{gpm} / \mathrm{f}^{2}\right)$ and $\mathrm{T}=$ time (minutes)

The $95 \%$ confidence interval for the time coefficient is $-1.4 \mathrm{e}^{-5}<\mathrm{c} 1<-0.00018$.

This indicates fouling of the filter during operation.

Figure 3. Filtrate Flux vs Time

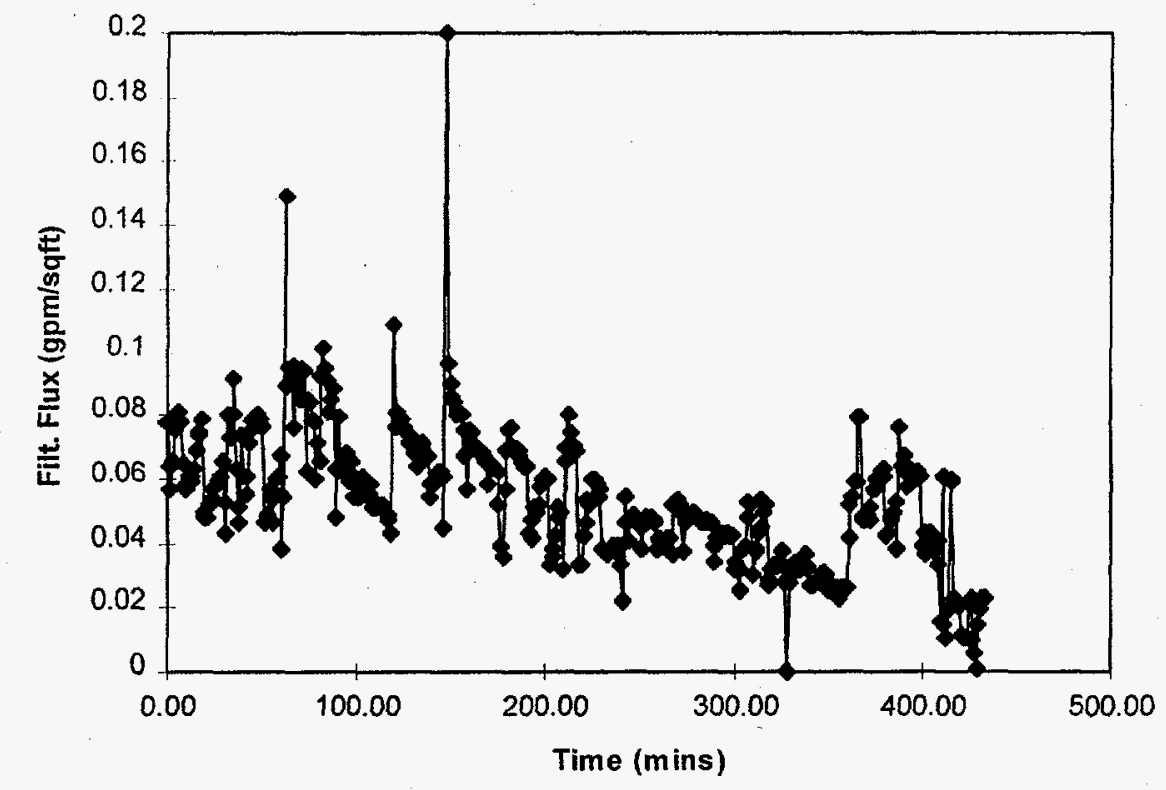

The spikes in filtrate flux were caused by backpulsing during the experiment.

Upon conclusion of the filter test, a cleaning step was employed. During this step, all the slurry was removed from the process vessel and process lines. These lines were then flushed three times in a once through pass. The process vessel was then filled with inhibited (pH 10) water that was recirculated for a period of 1 hour with periodic backpulses. Following this, the process vessel was again drained and refilled with 2 wt $\%$ oxalic acid. 
WSRC-TR-97-00352

Page 10 of 14

The oxalic acid solution was then circulated through the process loop for 60 minutes with periodic backpulses. Following 2 additional flushes with inhibited water, this process was repeated with a $2 \mathrm{wt} \% \mathrm{NaOH}$ solution with periodic backpulses. A measurement of the clean water flux was conducted and the oxalic acid, water, and $\mathrm{NaOH}$ treatments repeated until the measured flux was $80 \%$ of the values listed in the vendor literature (See Table 2 and 3).

\section{Table 2 - Clean Water Flux Before Filtration}

Mott Filter 1

\begin{tabular}{|c|c|c|c|c|c|}
\hline $\begin{array}{l}\text { Filter Inlet } \\
\text { Pressure } \\
\text { (psig) }\end{array}$ & $\begin{array}{l}\text { Filter Outlet } \\
\text { Pressure } \\
\text { (psig) }\end{array}$ & $\begin{array}{l}\text { Filtrate } \\
\text { Pressure } \\
\text { (psig) }\end{array}$ & $\begin{array}{l}\text { Vendor Lit. } \\
\text { Clean Flux } \\
(\mathrm{Gal} / \mathrm{hr})\end{array}$ & $\begin{array}{l}\text { Actual } \\
\text { Flux } \\
(\mathrm{Gal} / \mathrm{hr}) \\
\end{array}$ & $\%$ Clean \\
\hline 9.5 & 10 & 5.0 & 25.5 & 21 & 82.4 \\
\hline 19.5 & 20 & 11 & 35.5 & 30 & 84.5 \\
\hline 29 & 30 & 17 & 40 & 37 & 92.5 \\
\hline 39 & 40 & 24 & 48 & 42 & 87.5 \\
\hline 34 & 35 & 20.5 & 44 & 40 & 90.9 \\
\hline 24 & 25 & 14 & 39 & 33 & 84.6 \\
\hline 14 & 15 & 8 & 31 & 26 & 83.9 \\
\hline 40 & 40 & 24 & 48 & 42 & 87.5 \\
\hline
\end{tabular}

Mott Filter 2

$\begin{array}{llllll}\begin{array}{l}\text { Filter Inlet } \\ \begin{array}{l}\text { Pressure } \\ \text { (psig) }\end{array}\end{array} & \begin{array}{l}\text { Filter Outlet } \\ \text { Pressure } \\ \text { (psig) }\end{array} & \begin{array}{l}\text { Filtrate } \\ \text { Pressure } \\ \text { (psig) }\end{array} & \begin{array}{l}\text { Vendor Lit. } \\ \text { Clean Flux } \\ (\mathrm{Gal} / \mathrm{hr})\end{array} & \begin{array}{l}\text { Actual } \\ \text { Flux } \\ (\mathrm{Gal} / \mathrm{hr})\end{array} & \\ 11 & 10 & 6 & 25.5 & 22 & \text { \% Clean } \\ 21 & 20 & 11.5 & 35.5 & 33 & 86.3 \\ 31 & 30 & 20 & 40 & 40 & 100 \\ 41 & 40 & 27 & 48 & 44 & 91.7 \\ 35.5 & 35 & 23 & 44 & 42 & 95.5 \\ 26 & 25 & 26 & 39 & 36 & 90.0 \\ 16 & 15 & 9 & 31 & 28 & 87.5 \\ 41 & 40 & 27 & 48 & 44 & 91.7\end{array}$


Table 3 - Clean Water Flux After Filtration and Cleaning Treatment

Mott Filter 1

$\begin{array}{llllll}\begin{array}{l}\text { Filter Inlet } \\ \text { Pressure } \\ (\text { psig) }\end{array} & \begin{array}{l}\text { Filter Outlet } \\ \text { Pressure } \\ (\text { psig) }\end{array} & \begin{array}{l}\text { Filtrate } \\ \text { Pressure } \\ \text { (psig) }\end{array} & \begin{array}{l}\text { Vendor Lit. } \\ \text { Clean Flux } \\ (\text { Gal/hr) }\end{array} & \begin{array}{l}\text { Actual } \\ \text { Flux } \\ (\text { Gal } / \mathrm{hr})\end{array} & \text { \% Clean } \\ 9 & 10 & 5 & 25.5 & 20 & 78.4 \\ 19 & 20 & 10 & 35.5 & 30 & 84.5 \\ 29 & 30 & 17 & 40 & 36 & 90 \\ 39 & 40 & 23 & 48 & 42 & 87.5 \\ 34 & 35 & 20 & 44 & 40 & 90.9 \\ 24 & 25 & 14 & 39 & 34 & 87.2 \\ 14 & 15 & 8 & 31 & 25 & 80.6 \\ 39 & 40 & 23 & 48 & 42 & 87.5\end{array}$

Mott Filter 2

Filter Inlet Filter Outlet Filtrate Vendor Lit. Actual

Pressure Pressure Pressure Clean Flux Flux

$\begin{array}{lllll}(\mathrm{psig}) & (\mathrm{psig}) & (\mathrm{psig}) & \underline{(\mathrm{Gal} / \mathrm{hr})} \quad \underline{(\mathrm{Gal} / \mathrm{hr})} \quad \text { \% Clean }\end{array}$

$\begin{array}{llllll}11 & 10 & 5 & 25.5 & 22 & 84.6 \\ 20 & 20 & 11 & 35.5 & 31 & 86.1 \\ 30 & 30 & 19 & 40 & 39 & 97.5 \\ 40 & 40 & 26 & 48 & 43 & 89.5 \\ 35 & 35 & 22 & 44 & 42 & 95.5 \\ 26 & 25 & 15 & 39 & 36 & 90 \\ 16 & 15 & 9 & 31 & 28 & 87.5 \\ 40 & 40 & 25 & 48 & 42 & 87.5\end{array}$

Particle size distribution data were collected on the simulated waste samples. Particle size analyses were conducted using a Microtrac II, Series 7998 Particle Size Analyzer. The range of this instrument is 0.7 to 700 microns. Three columns of data are presented in Table 4: the particle diameter below which 10,50, and 90 volume percent of the particles lie. For example, the first filtrate sample had $10 \%$ of the sample particles less than 46 microns, $50 \%$ of the sample particles less than 84 microns, and $90 \%$ of the sample particles less than 142 microns. 
WSRC-TR-97-00352

Page 12 of 14

Table 4 - Particle Size Data

$\underline{\text { Sample Description }}$

Filtrate

Filtrate

Slurry (no pumping)

Slurry ( $8 \mathrm{hrs}$ pumping)

Slurry (16 hrs pumping)
$10 \%$ (microns)

46

46

35

45

48 $\underline{50 \% \text { (microns) }}$

84

81

68

79

86
90\% (microns)

142

124

115

123

150

The results of the slurry and filtrate samples give relatively the same particle size range, the filtrate apparently formed a precipitate after the sample was taken. No appreciable change in particle size was observed during pumping indicating that shearing is not occurring which makes particle size smaller. In previous filter studies when particle size does not stay within a close range we have seen a change in viscosity. Since the particle size is within a close range viscosity in this slurry should not change appreciably.

Rheology instrumentation on the filter apparatus was not effective in giving reliable viscosity data because of the surges and problems in controlling flow and pressure due to the nature of pumping the slurry. 
WSRC-TR-97-00352

Page 13 of 14

\section{Conclusions}

- The 0.5 micron Mott filter does not give good solid-liquid separation because solids formed in the filtrate after the filtration process. A longer cooling period may have allowed the solution to reach equilibrium and prevented post-precipitation.

- Steady state control of pressure and the axial slurry flow rate was difficult; possibly because of the turbulence caused by the precipitate particles in the feed tank, the adhesiveness of the solids, or their size.

- Filter cleaning after filtration is possible using $2 \mathrm{wt} \% \mathrm{NaOH}, 2 \mathrm{wt} \%$ oxalic acid, and deionized water treatments with backpulsing.

- Filtrate flow has been shown to be dependent on filter differential pressure but not on slurry velocity. This indicates formation of particles in the pores of the filter but not on the filter surface. Solid deposition in the pores would not be affected by increases in axial velocity because the filter cake would not be exposed to the bulk slurry flow. Since there is no filter cake on the filter surface then back transport of rejected slurry particles should not play a role in filter performance. Also, there would not be any significant boundary layer interactions because these generally only form on filter cakes located on the filter surface.

- Filtrate flux was found to be dependent on time, indicating filter fouling during filtration. 
WSRC-TR-97-00352

Page 14 of 14

Acknowledgments

This work was done as part of the DOE Office of Science and Technology, Tanks Focus Area program (TTP SR-16WT-41); C.P. McGinnis, Pretreatment Technical Integration Manager; D. Geiser, Office of Science and Technology Program Manager.

References

1. WSRC-TR-95-0337, "Evaluation and Ranking of the Tank Focus Area Solid Liquid Separation Needs (U)", D.J. McCabe, June 17,1995.

2. "Sludge Treatment Studies", ORNL/TM-13371, June 1997, E.C. Beahm, C.F. Weber, T.A. Billow, S.A. Bush, S.Y. Lee, and R.D. Hunt.

3. WSRC-TR-95-0420, "Filter Performance Mechanisms", R.A. Peterson, C.A. Nash, October 1995.

Authors
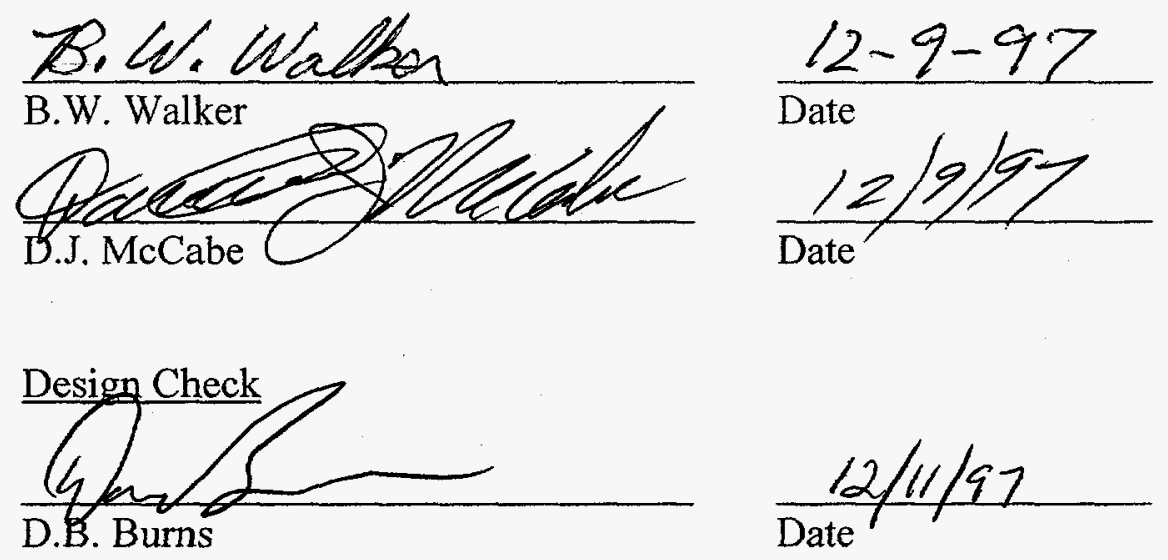

Level 4 Manager

$\frac{\text { W.B. Uam Pelt }}{\text { W.B. Van Pelt }}$

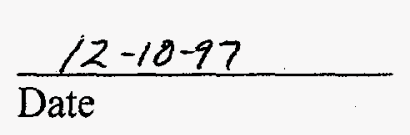

Level 3 Manager

LE tome

W.E. Stevens

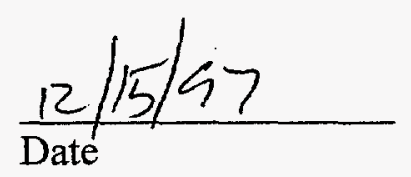

